\title{
aniki
}

Revista Portuguesa da Imagem em Movimento

Portuguese Journal of the Moving Image

\section{Poética Audiovisual da Precariedade: uma análise da websérie Leona Vingativa}

\section{Plynio Nava}

Programa Interdisciplinar de Cinema e Narrativas Sociais/PPGCINE, da Universidade Federal de Sergipe/UFS, São Cristóvão

plynionava86@gmail.com

https://orcid.org/0000-0003-4897-1482

\section{Claudiene Santos}

Programa Interdisciplinar de Cinema e Narrativas Sociais/PPGCINE e Departamento de Biologia/DBI/CCBS da Universidade Federal de Sergipe/UFS, São Cristóvão

claudienesan@gmail.com

http://orcid.org/0000-0002-2337-9370

\section{Francisco A. Zurian}

Grupo de Investigación GECA: Género, Estética y Cultura Audiovisual de la Universidad Complutense de Madrid, Facultad de Ciencias de la Información, Ciudad Universitaria

azurian@ucm.es

http://orcid.org/0000-0002-3734-6879

RESUmo Este artigo discute a precariedade como categoria poética no audiovisual, abordando sua relação com o vídeo e sua influência nas produções amadoras contemporâneas, ao analisar a websérie Leona Vingativa sob a perspectiva da poética do cinema e do Queer Caboclo. Esta perspectiva institui a categoria da margem, do fora-de-cena, das autorrepresentações e dos ecos das vozes subalternizadas, a fim de refletir suas interações, influências, anseios e modos de ver, os quais fundamentam uma nova ordem sensível e contracultural. Assim, a figura do Queer Caboclo, do corpo amazônico, com seus traços e performatividades, esboça uma nova virada epistemológica, cujos reflexos revelam contradições e retóricas contestatórias que interferem nos critérios formais e conceituais da cultura de massa, resultando num processo de rearticulação de significados a partir de um viés político e subversivo.

PalavRas-Chave Precariedade; vídeo amador; webséries; Leona Vingativa. 


\section{Introdução}

A proposta deste texto é problematizar a categoria da precariedade como um apêndice e reflexo do ensaio Diversidade Sexual e de Gênero e Novos Descentramentos: Um Manifesto Queer Caboclo (Fernandes, Estevão e Gontijo 2016), discutindo-a como estética audiovisual do vídeo amador, a partir da análise da websérie Leona Vingativa sob a perspetiva da poética do cinema. Situando-a no âmbito de produções audiovisuais do 'cinema de bordas' (Lyra 2009) analisamos a manifestação audiovisual da precariedade, tomando de empréstimo o protagonismo do corpo amazônico, os afetos ressemantizados da cultura de massa e as relações com a estética do vídeo amador, enfatizando aspetos como representação do espaço, mise-en-scène e qualidade da imagem, refletindo sobre a categoria em produção. Desse modo, a primeira secção apresenta os conceitos de precariedade, Queer e Queer Caboclo. Na segunda secção, as transformações ocorridas no cinema com o advento do digital são discutidas. A terceira secção traz uma breve apresentação da cultura direct $w e b$ na consolidação da ficção online e, por fim, desenvolvemos o conceito de poética da precariedade a partir da análise da websérie Leona Vingativa. Concluímos que a poética da precariedade não apenas apresenta uma crítica às representações hegemônicas da imagem, mas incorpora o domínio das autorrepresentações para situar seus efeitos estéticos e políticos na crítica sobre identidade, representação e imaginário, ampliando, dessa forma, novos usos, práticas e olhares sobre a produção visual contemporânea.

Ao analisar as diretrizes do espaço, mise-en-scène e imagem como expressões poéticas do precário, este artigo contrapõe-se aos ideários de conformação, trazendo novas pedagogias do olhar e desafiando processos de domesticação, hegemonia e gosto, incorporando o não-lugar, o não-ser e o devir como agências estético-políticas que superam modelos de normalização. Desse modo, estas diretrizes interferem ativamente nos códigos da linguagem e estética, incorporando camadas significantes às representações institucionalizadas do espaço, da performatividade e da imagem veiculadas pelos textos audiovisuais que abordam a Amazônia queer sob o filtro dos estereótipos e dos olhares colonizados que incidem sobre o Queer Caboclo e os corpos amazônicos.

Ao trazer vozes subalternizadas, visualizam-se textos contra-hegemónicos que ressignificam lugares, ideias e contextos, a partir de um novo olhar que integra condições materiais, não mais como expressões resignadas pelo fetiche da miséria e desigualdade. Ao contrário, refletem suas 
condições como crítica das representações, embutindo outros significados, agências e sensibilidades possíveis, em que o capitalismo reflete a sua maquinaria e nas quais os seus produtos emergem como vetores que se voltam contra seus efeitos para intervir nas retóricas de dominação e silenciamento.

\section{Aproximações entre o queer, Queer caboclo e precariedade}

Para articular aproximações entre estudos queer e precariedade é imprescindível retornar à formação do Estado e à contribuição da ideologia como fundamento de sua consolidação. Com a fragmentação advinda do processo de divisão social do trabalho, o Estado emerge apresentando-se como um corpo universal, a-histórico, neutro e totalizante de valores, leis, discursos e parâmetros de organização, cuja dinâmica se estabelece em condições historicamente determinadas, relações socialmente construídas e condições materiais favoráveis à sua estabilização. A sociedade é ordenada nos termos de um paradigma excludente em cujos valores, visões de mundo, cultura e modos de pensar está embutida a ideologia de uma elite privilegiada, que ecoa sua influência nas instituições, tecnologias e dispositivos discursivos a uma parcela majoritária e introduz um discurso com ares de objetividade, a fim de estabelecer consensos. No fragmentário espaço social no qual atua esta complexa engenharia, retroalimenta-se o ilusório ideário universalista que torna invisíveis interesses particulares, relações de poder e exclusão social que dele são decorrentes.

Todavia, é no âmbito das sexualidades dissidentes como dimensão da linguagem, que se estruturam discursos, que produzem materialmente a opressão num modelo sociocultural ancorado no pilar heteronormativo. Assim, uma perspectiva queer, interseccional e feminista não apenas sinaliza o caráter interrelacional dos marcadores étnico-raciais, de classe, gênero e sexualidade, que sobrepõem exclusões socialmente naturalizadas, mas apresenta estratégias estético-políticas que, baseadas nestas convergências, fraturam as bases normativas, que fundamentam a ordem hegemônica nesta rede de signos, narrativas, discursos e representações chamada de linguagem. Embora compreendamos que nem todas as manifestações de opressão advêm de um sistema baseado na divisão social de classes, a este sistema se adaptam e nele se perpetuam. Rea e Amancio $(2018,3)$ corroboram esta ideia, dizendo que "enquanto lugar de subalternidade continuamente ressignificado, as teorias e 
práticas queer fazem parte destas experiências culturais anti-hegemónicas, de contestação da sociedade normativa e das suas múltiplas formas de exclusão".

A linguagem emerge como uma instância onde se realizam negociações de grupos historicamente marginalizados, cujas disputas por justo reconhecimento e distribuição (Fraser 2017) expressam reivindicações de igualdade participativa na vida social, pois tais injustiças estão diretamente relacionadas à integração de padrões excludentes no âmbito institucional, que refletem disparidades concretamente experenciadas. É neste contexto que a ideologia manifesta sua influência mais expressiva, pois oferece obstáculos à consolidação de políticas de igualdade, participação e justiça social entre comunidades sexualmente dissidentes marcadas pela sobreposição de múltiplos marcadores sociais, dando concretude ao que Butler (2015) definirá como precariedade, entendida como uma condição estabelecida por forças hegemónicas que submete existências a distintas formas de opressão, violência e morte.

As formas precárias estão estreitamente alinhadas a estratégias de enquadramento determinadas por instâncias políticas, cujas construções representativas incluem a possibilidade de afetar as condições nas quais algumas vidas serão consideradas e, quais delas serão passíveis de luto e humanidade. A discussão acerca da precariedade amplia as contribuições de Butler (2000) ao seu conceito de abjeção, termo constituinte das relações de poder, cuja formação e sedimentação acontece a partir da produção de corpos repulsivos e ininteligíveis, necessários à produção de sujeitos socialmente reconhecidos. Portanto, para consolidar esta produção, recorre-se à produção de um 'outro', cujas marcas de sexo, sexualidade e raça são necessárias para homologação de uma identidade normativa. Em comum, ambas as categorias sinalizam a definição do corpo numa relação de poderes que estabelecerão contornos, limites e fronteiras para a composição de uma existência aceitável ou excluída nos processos de inserção que atravessam uma determinada ordem sociocultural. Aqui, a categoria do enquadramento (Butler 2011) oferece contribuição para entendimento das implicações decorrentes dos processos de apreensão destes corpos pela linguagem midiática tradicional. Essa apreensão faz-se através de processos de exclusão e violência em que estes corpos são vítimas, uma vez que é no âmbito destas linguagens que são fortalecidos os critérios pelos quais uma existência goza ou não do status de sujeito. Como Butler argumentou: 
O processo de esvaziamento humano feito pela mídia, por meio da imagem, deve ser entendido, no entanto, nos termos do problema mais amplo de que esquemas normativos de inteligibilidade estabelecem aquilo que será e não será humano, o que será uma vida habitável, o que será uma morte passível de ser lamentada. (Butler 2011, 28)

A constituição de corpos humanizados atua no complexo território de significação da linguagem, mediando relações sociais e estabelecendo paradigmas de normatização cuja estabilidade depende do exercício de suas instituições. Na linguagem, reafirma-se a ideologia vigente, mas também estratégias de negociação para os justos termos de reconhecimento e distribuição. Seus reflexos se materializam na extrapolação da experiência destes corpos no âmbito de uma poética da precariedade. Assim, reconhecem processos de vulnerabilidade e usam tais circunstâncias em favor de formas de afirmação política em vez de conformismo.

Esforços em torno de intervenções nos códigos semânticos (como no pajubá), na reivindicação da linguagem neutra inclusiva de pessoas não-binárias, na capacidade subversiva da cultura drag ao representar a artificialidade do género, ou mesmo da formação de comunidades em torno do voguing (fim séc. XX), em bairros estadunidenses de maioria negra e latina (anos 1980), são exemplos de resistências ao status quo. Surgem como ações que não somente expressam limites de uma institucionalidade baseada em critérios excludentes de paridade participativa, mas também tornam mais claras as consequências concretas da ideologia heteronormativa na distribuição desigual de prerrogativas de justiça social, inclusão e visibilidade nos campos da produção de significados, que atravessam o tecido social. Neste sentido, Borba complementa:

Já que somos construídos através do que falamos (...), ao falar utilizamos discursos que temos disponíveis, e esses discursos podem ecoar (repetir e reiterar) as normas da heteronormatividade, nos impelindo, assim, a posições de sujeitos com as quais não necessariamente nos identificamos. (Borba 2015, 99)

Tais práticas recorrem aos expedientes da linguagem, a fim de confrontar coletivamente as ameaças do poder contra sua invisibilidade, conforme sinalizam as experiências audiovisuais que, desde meados de 1980, instituem pactos de intimidade com o público, configurando uma 
visualidade háptica (Marks 2000), para instaurar um regime estético-político que rompa fronteiras entre eu e outro, emissor e recetor, espectador e imagem. Assim, constituem uma espécie de epiderme comum, que aproxima tais instâncias e estabelecem novas políticas de sentido. A linguagem audiovisual produz estranhamentos na abordagem das relações entre corpo e espaço, ficção e realidade, alta e baixa cultura e sujeito e objeto, numa complexa rede semântica que tem na experiência dos corpos queer seu vetor desestabilizador.

Neste contexto, interessa-nos aproximarmos do Queer Cabloco, virada política centrada numa perspectiva epistemológica contrarreproduvitivista. Esta virada aborda uma perspectiva não-integracionista, "um contraponto radical às dinâmicas desde as quais estes outros lugares são esvaziados de seu potencial de crítica aos processos de heteronormatização, enquadramentos coloniais, domesticação do corpo e dos afetos" (Fernandes, Estevão e Gontijo 2016, 18). Compreende práticas correntes que substituem o locus político pela corroboração de posições, imersas no ethos do discurso acadêmico, em cujo núcleo ecoam os modelos de institucionalidade, bibliografia, imparcialidade e não-envolvimento, os quais envolvem dinâmicas de poder e dominação. Sua proposta é integrar envolvimento e visceralidade, entrecruzando posições sexuais, étnicas e raciais que desafiem os rumos da política brasileira no campo das reflexões e debates recentes acerca da diversidade sexual e de gênero. Resgata culturas não-centradas, estéticas marginais e éticas periféricas, que se distanciam das estruturas de sensibilidade orientadas pelo ideário colonizado da branquitude heterossexista e urbana.

0 manifesto Queer Caboclo institui a categoria da margem, do fora-de-cena, das autorrepresentações e dos ecos das vozes subalternizadas, a fim de refletir suas interações, anseios e modos de ver, os quais fundamentam uma nova ordem sensível e contracultural. Assim, disputam-se espaços e olhares, desafiam-se narrativas e pautam-se debates sobre corpo, gêneros e afetos numa pluralidade de campos expressivos. A figura do Queer Caboclo, do corpo amazônico, com seus traços e performatividades, esboça então uma nova virada epistemológica, cujos reflexos revelam retóricas contestatórias que interferem nos critérios formais e conceituais da cultura de massa, resultando na rearticulação de significados, a partir de um viés político e subversivo.

As transformações no estatuto da imagem, com o advento do vídeo, tiveram como consequência uma discussão sobre o caráter realista da 
produção audiovisual, em decorrência de seu forte grau de manipulação (Felinto 2006). Factos como a popularização da rede mundial de computadores, a cibercultura e o barateamento dos dispositivos de captação de imagem produziram uma onda audiovisual caraterizada por forte apelo à intimidade, firmando um domínio de produções alinhadas com protocolos de hipervisibilidade e exploração da subjetividade. Tal fenómeno carateriza-se pela emergência da categoria do amador como potência que desestabiliza textos hegemónicos sobre a arte e cultura, a fim de habilitar a dimensão poética destas produções, comumente difundidas em sites de compartilhamento de vídeo, como Dailymotion, Vimeo e, sobretudo, o YouTube.

Defendemos a ideia de que a precariedade surge como manifestação estética e política, ao voltar sua atenção para os modos como tais produções, pautadas pela autorrepresentação, sinalizam a autonomia da alteridade na construção de narrativas, representações e textualidades que vão de encontro aos discursos institucionalizados pela mídia hegemónica.

\section{Da ontologia da imagem fotográfica à desmaterialização digital}

Escrito, em 1945, por André Bazin (1991), o ensaio Ontologia da Imagem Fotográfica discute o estatuto do cinema, que impulsionou uma corrente de pensadores com linhas de pensamento plurais que convergiam na discussão sobre o realismo. Para Bazin, a questão realista da fotografia era proveniente de sua forma de produção, uma vez que a revelação da imagem registrada no filme fotográfico era submetida a um processo que consistia na exposição de cristais de prata imersos na emulsão fotográfica, gerando uma alteração química que daria origem à imagem visível. 0 caráter realista defendido por Bazin advinha, portanto, da não-intervenção humana num processo de revelação que estava estritamente vinculado a fatores como temperatura, luz e tempo. Nas palavras do autor:

Pela primeira vez, entre o objeto inicial e sua representação nada se interpõe, a não ser um outro objeto. Pela primeira vez, uma imagem do mundo exterior se forma, automaticamente, sem a intervenção criadora do homem, segundo um rigoroso determinismo. (Bazin 1991, 22) 
Se, na retrospectiva sobre as artes de Bazin, a necessidade de vencer o tempo é um dado que acompanha o homem desde os seus primórdios, um divisor de águas parece estabelecer rupturas em contextos históricos tão díspares: a substituição do ideal mágico, presente nas gravuras das cavernas e nas técnicas de embalsamamento, pela avidez da semelhança, buscada pelas artes plásticas, no século XV. Para Bazin $(1991,20)$, "se a história das artes não é somente a de sua estética, mas antes a de sua psicologia, então ela é essencialmente a história da semelhança, ou se se quer do realismo".

No debate contemporâneo, o surgimento da imagem digital coloca em xeque os pressupostos da verossimilhança, discorridos pela teoria realista do cinema, para implantar uma rearticulação de seu estatuto por sua revolução técnica. Essa rearticulação diz respeito à substituição do processo químico de produção imagética, que isentava o homem de intervenções diretas na fotografia, pela emergência de um novo modelo de imagem móvel, caraterizada pelo alto grau de manipulação. Conforme argumenta Felinto $(2006,425)$, "Em sua extrema flexibilidade, a imagem digital permite um grau de manipulação inacessível ao analógico - e, portanto, em alguns sentidos, capaz de absorvê-lo. Essa flexibilidade deriva, essencialmente, de sua descontinuidade."

Nascida no contexto de grande industrialização, avanços da informática e desenvolvimento da linguagem artificial, o digital tem seu ápice na década de 1960, com o expanded cinema. Formado por realizadores como Nam June Paik, Stan Van der Beek e Malcolm Le Grice, o principal objetivo deste movimento era afirmar a potência artística do vídeo, ao abandonar as convenções cristalizadas, anteriormente, com o cinema narrativo feito em película, e explorar a textura da imagem, modos de perceção, ampliação dos espaços de projeção (Zanini 2006) e, sobretudo, maior participação do espectador. 0 projeto de elaboração de uma poética do vídeo, pano de fundo do movimento, atualizou pressupostos das vanguardas históricas ao assumir o desejo de aproximação entre arte e vida. Preconizando a transcendência das salas de cinema, o cinema expandido daria sinais de esgotamento de seus moldes tradicionais e prenunciaria o gradual processo de cooptação da imagem digital pelo mercado, com a ascensão da cultura home video (VHS) e a popularização das videolocadoras. Entretanto, abriria precedentes para nova abertura na linguagem audiovisual ao insistir nas possibilidades artísticas do vídeo pela intensa domesticação de sua linguagem. 
A imagem digital surge num contexto de várias transformações na informática, telecomunicações e dos primeiros experimentos que dariam origem à internet (Felinto, 2006). No momento em que os debates em torno do simulacro, da desmaterialização dos meios e da expansão das formas de produção, difusão e consumo da imagem móvel parecem tornar a categoria do real questionável, assiste-se a uma reconfiguração da cultura audiovisual, na qual o intercâmbio de espaços entre realizador e espectador se torna instável e sujeito à produção de uma nova ordem na economia cultural das imagens. Quais as consequências dessa mudança paradigmática, favorecida pelo uso artístico da imagem digital? Quais as implicações das novas formas de fruição pretendidas por tais produções? Que papel a interatividade prenunciada pela videoarte tem na construção do novo panorama audiovisual, gestado na atualidade?

Na década de 1990, a integração de computadores numa rede mundial possibilitou o ciberespaço (Levy 1999), em que usuários compartilham conteúdos, informações, comunicam e produzem cultura. Nele, a interatividade é a marca da nova relação entre meios e pessoas, caraterizada pelo uso colaborativo que, gradualmente, afasta usuários da posição passiva, tradicionalmente estabelecida pelo rádio, televisão, imprensa, para colocá-los num ambiente expansivo, reunindo usuários de todo o globo terrestre em relações distintas de intercâmbio, criação e difusão de conteúdo (Levy 1999).

Entretanto, a consolidação efetiva do ciberespaço foi possível graças aos avanços em torno de um novo modelo de rede, consolidado com o surgimento da web 2.0 (O'Reilly 2007). Esta pode ser entendida como uma geração mais avançada de serviços da rede: uma inteligência coletiva online, onde o grau de participação dos usuários se potencializa e a própria internet se transforma num espaço onde redes sociais, blogosfera e o hipertexto refletem uma perceção mais categórica da cultura colaboracionista. Assim, a web permitiu aos seus usuários contribuir para sua arquitetura. Aspetos relacionados com a personalização das páginas, tecnologias RSS ${ }^{1}$, popularização da banda larga e barateamento de gadgets como telefones celulares, câmeras digitais e outras mídias permitiram construir um território marcado pela emergência do audiovisual como uma de suas principais expressões difusoras. Resumidamente, a web 2.0

${ }^{1}$ Sigla em inglês para Rich Site Summary, tecnologia criada para armazenar grande volume de informação num site de forma simplificada e resumida. 
pode ser entendida assim: de um lado, estão conteúdos audiovisuais produzidos e difundidos na internet (trailers, filmes, programas televisivos) e, do outro, conteúdos produzidos para a internet (canais de videologgers no Youtube, microvídeos produzidos em aplicativos como Snapchat, provedores de conteúdo via streaming e outros).

Num momento em que a hipervisibilidade deixa marcas profundas numa sociedade conectada por celulares, tablets, computadores e outros aparelhos com câmeras acopladas, as implicações desse processo dão conta de uma revitalização do amadorismo (Polydoro e Costa 2014) como estética que atravessa produções e encontra em nichos virtuais um lugar privilegiado de distribuição. Um aspeto interessante com o fenómeno dos vídeos amadores está diretamente relacionado ao seu efeito dialético com protocolos do cinema já consolidados, facto que torna visível uma reabilitação do realismo, deixado em segundo plano com o advento da imagem digital.

Acompanhando um processo iniciado com a ascensão dos filmes de película caseiros, a estética amadora fundamenta-se hoje, primordialmente, no ciberespaço, onde circulam produções que trazem a emergência da subjetividade como marca fundamental e a elaboração da identidade, memória e intimidade num contexto sociocultural descentralizado e mais independente. Se não há critério de autenticidade no que é produzido pela estética amadora dos anos 2000, é inegável considerar suas implicações na discussão acerca da hipervisibilidade, sua influência em produções cinematográficas e, sobretudo, o resgate de um realismo que já não se justifica na ontologia da imagem fotográfica baziniana, mas na conjunção de marcas expressivas que tornam explícita a presença da alteridade a quem outrora os protocolos de representatividade midiática recusaram o reconhecimento da autonomia.

\section{Bordas desmaterializadas: cultura direct to web e o advento da ficção online}

O YouTube entra em cena como signo da cultura participativa, com o advento do ciberespaço. 0 site surgiu no início dos anos 2000 e tem como moeda de troca os milhões de vídeos produzidos, visualizados e compartilhados diariamente numa plataforma cujo catálogo inclui filmes, videoclipes e outras produções, que o consolidaram como um dos maiores serviços de internet do mundo (Burgess e Green 2009). No entanto, é através de uma categoria distinta de produção - os vídeos amadores - que 
o site mostra sua relevância no âmbito do debate sobre a produção de conteúdos independentes, pois torna possível aos usuários compartilhar cenas corriqueiras, opiniões sobre banalidades cotidianas e outros rituais, os quais projetam a intimidade do público a milhões de usuários espalhados pelo mundo. "O slogan do YouTube é "Transmita-se a si mesmo". E transmitir a nós mesmos é o que fazemos, com toda a autoadmiração desavergonhada do Narciso mítico" (Keen 2009, 12).

Se, na década de 1990, o mercado audiovisual se adaptava a um modelo de produção de conteúdos feitos diretamente para o VHS, o surgimento de plataformas como YouTube, Vimeo e Dailymotion atualiza essa configuração, formulando um novo paradigma: produções audiovisuais feitas diretamente para a rede. 0 conceito de "amador", que atravessa as produções desde o cinema feito em película, novamente se metamorfoseia na esfera virtual, graças à estrutura de tais sites. Gunning (2006) analisa os primeiros cinemas e conceitua a atração como premissa que se fundamenta na hipótese de um cinema narrativo, que convida o espectador ao voyeurismo, e de um cinema não-narrativo, que o convida observar sua faceta exibicionista. Para Gunning, a história do cinema tem sido escrita de modo a privilegiar uma conceção evolucionista que forja em suas produções pioneiras um emblema primitivo, superado com o advento do cinema narrativo. Este autor reflete sobre estes dois modos de cinema, tentando não somente explicitar circunstâncias, influências e contextos, mas criticar a conceção evolucionista das imagens móveis, chegando a pontuar a retomada - e relevância - do cinema de atrações em produções vinculadas a uma proposta vanguardista que se apropria da retórica das atrações a serviço da criação de novas formas de contar histórias, da preservação de hibridismos estéticos e da ampliação das esferas de fruição.

Sob a influência dos pressupostos de Gunning acerca do modelo de cinema de atrações, em produções posteriores à consolidação do cinema narrativo, Rizzo (2008) analisa a atualidade dessa forma de exibição, tomando de empréstimo sua influência no campo das produções compartilhadas no YouTube, fortemente influenciadas pelo caráter exibicionista, chocante e espetacularizado dos filmes de atração. Tal consideração pode ser analisada, preliminarmente, pelo modo como as produções são estruturadas no site, que apresenta uma série de vídeos que se ligam entre si por critérios distintos e produz no usuário uma forte sensação de desorientação, proveniente da infinidade de ofertas apresentadas. Para Rizzo, "assim como no cinema de atrações, o YouTube 
é um meio exibicionista que gira em torno de atos de exibição" (Rizzo 2008). Dos clipes aos vídeos caseiros, passando por filmes e produções de variados videologgers, o YouTube potencializa a função exibicionista e atrativa dos primeiros cinemas, para chamar atenção para si próprio. Como uma variação das primeiras feiras que integravam atrações - entre elas, o próprio cinematógrafo - ele convida o espectador a ver seus vídeos, colocando-o numa situação que o divide entre a curiosidade, a surpresa e a sensação de novidade trazida por cada vídeo.

Rizzo (2008) pontua um detalhe especial: o caráter alusivo de suas produções. Esse efeito remediador, que se apresenta, primordialmente, nos videoclipes, filmes online e webséries caseiras tem como influência assuntos abordados pelo cinema e telenovelas, utilizando suas convenções e sofisticando códigos em contextos de interesses distintos. Se, até então, o fascínio das imagens móveis provinha da captação do movimento, atualmente, o modo das atrações demonstra seu interesse pelo intertexto.

Neste debate sobre atualizações do cinema amador com o advento da cibercultura, surge outra categoria cinematográfica: o cinema de bordas. Lyra (2009) divide as produções audiovisuais em três grupos: o primeiro corresponde aos filmes convencionais que circulam no ambiente mainstream, nos quais atores famosos, narrativas que giram em torno de sentimentos, ações e intenções, marcadamente comerciais, se apresentam como suas principais caraterísticas. No segundo grupo, estão produções que estreitam diálogos com subculturas, nas quais realizadores cinéfilos, conhecimento técnico e crítica ao modelo industrial de cinema são marcos norteadores. No terceiro grupo, incluem-se produções de realizadores autodidatas, moradores de periferias e comunidades afastadas dos grandes centros urbanos, nas quais a precariedade técnica, uso de câmeras baratas, atores não profissionais e exibição em salas improvisadas são suas principais caraterísticas. Nesse último grupo, encontra-se o cinema de bordas, um tipo de produção elaborada por realizadores sem formação que, localizados em espaços distantes dos grandes centros, investem em produtos audiovisuais pautados em narrativas inspiradas na cultura de massas, em géneros cinematográficos mainstream e no imaginário alimentado pela influência televisiva. Distanciando-se do modelo oposicionista de tradições cinematográficas do cinema marginal, o cinema de bordas não está ancorado numa proposta experimental, mas num processo insistente de antropofagia, que se alimenta dos signos da cultura popular veiculados pelo cinema e televisão, resultando em produções de baixíssimo orçamento, caraterizadas pela ausência de domínio da 
mise-en-scène, imagens de baixa resolução, planos não elaborados e pouca habilidade de montagem.

Recentemente, o cinema de bordas tem sofrido adaptações, decorrentes das facilidades de difusão de conteúdos pela internet. Produções alcançam milhares de visualizações em sites de compartilhamento de vídeos, ganhando popularidade entre usuários, o que confirma o potencial de tais espaços na popularização de obras que não teriam espaço nos sites de crítica de cinema, tampouco nos catálogos de mostras de grandes centros urbanos. No intenso diálogo entre audiovisual e internet, a marca do amadorismo permanece indelével em muitas produções recentes. Ainda que o ingresso de pequenas e médias produtoras tenha migrado para o ciberespaço e a ascensão de provedores via streaming tenha gerado receitas a seus fundadores, a estética do filme amador continua na contramão das expetativas de mercado, investindo nas retóricas da hipervisibilidade, do realismo das representações e no amadorismo como sua marca registrada.

\section{Poética da precariedade: a estética de bordas na websérie Leona Vingativa}

Exploremos as articulações entre o conceito de precariedade, o Queer Cabloco e o cinema de bordas na websérie Leona Vingativa. 0 surgimento e ascensão da personagem Leona Vingativa podem ser assim resumidos: com oito anos de idade, alguns amigos e uma câmera de baixíssima resolução, Leona decide gravar vídeos e publicá-los na internet. Feitas despretensiosamente, as produções ganharam popularidade na rede, até se consolidarem como um webhit. Moradora do Jurunas, um dos mais populosos bairros periféricos de Belém/PA, Leona desponta como uma personagem que repercute nacionalmente, graças ao sucesso de Leona Vingativa, websérie de quatro episódios que explora a saga da protagonista homónima rumo a Paris. A trama se inicia quando a personagem Aleijada Hipócrita descobre que Leona assassinou o marido. A partir daí, a protagonista se desdobra em várias situações para fugir da polícia. Inspirada no melodrama das telenovelas mexicanas, com estética de vídeo amador, Leona Vingativa reafirma o debate acerca da potência da precariedade na arte contemporânea e a construção de textos baseados numa normativa da autorrepresentação da vivência gay no norte amazônico, periférico, de onde "a proposta de um Queer Caboclo, 
amazônida, ribeirinho, nos impõe a premência de uma epistemopolítica contrarreprodutiva" (Fernandes, Estevão e Gontijo 2016, 18).

Num contexto sociocultural em que os protocolos canónicos de crítica, produção e difusão de produtos são colocados em xeque por textos culturais e obras artísticas, o precário ressurge como potencial de desestabilização das verdades cristalizadas nos discursos acerca da cultura, para revelar potencialidades subversivas de espaços, produtos e existências marginalizadas em "produções que tematizam a precariedade, a pobreza e que, em muitas de suas realizações, literalmente se servem de restos como material, ao mesmo tempo que, conceitualmente, colocam a perturbadora questão ética de conservação e resistência da memória dos excluídos do sistema" (Cury 2013, 36). Para Villar (2014), o conceito de precariedade é uma das principais chaves para compreender as produções de arte contemporânea. Para ele, a presença da precariedade não se institui como novidade na história, mas se intensifica com a consolidação da sociedade capitalista hipermoderna. Se antes da crise mundial de 2008, o conceito parecia estar envolvido por uma aura anacrónica, hoje se apresenta como tradução do contemporâneo. 0 ceticismo, insegurança e incerteza em relação ao futuro flutuam no imaginário social, e transparecem de forma mais categórica os reflexos da contingência e da efemeridade, presentes desde o surgimento das vanguardas históricas.

Num momento em que dúvidas se firmam de maneira incisiva sobre o porvir, a precariedade deixa sua marca no âmbito das produções culturais, ao refletir a efemeridade, desmaterialização e desestetização nos textos da cultura e nas obras de arte. Se sua influência não deixa dúvida quanto à atmosfera de incerteza que paira sobre o mundo, é justamente essa circunstância que permite dinamizar novos ciclos e mudanças. A precariedade, para Villar (2014, 79) "não é necessariamente uma desordem no sentido de uma doença. Trata-se de uma desordem que cria uma nova ordem para as obras de arte e as práticas estéticas, para os públicos e as audiências, e para o juízo estético e a crítica de arte”. 0 audiovisual se firma, então, como um dos principais campos de gestação de produtos culturais inspirados pelo contexto de precariedade, constituindo um terreno que dinamiza e desconstrói modelos de fruição ao agregar em suas obras a forte influência da estética amadora, tal como visualizamos na websérie Leona Vingativa.

Esta websérie será analisada nas secções seguintes sob a perspectiva da poética do cinema, método que objetiva entender o filme como uma programação de efeitos (Gomes 2004). Inspirada no tratado acerca da 
ficção proposto pela poética aristotélica, a análise obedecerá a três critérios, representados pela dimensão dos efeitos, estratégias e s recursos que, uma vez decompostos, elucidarão o processo de organização interna da obra audiovisual.

Ao estabelecer o filme como composição, na qual a interação dos dispositivos e estratégias constituirá o cerne da experiência cinematográfica, este método elencará, e investigará como se organizam numa obra os aspetos relativos ao campo das sensações, sentimentos e sentidos imersos no filme, de modo a reconhecer sua prevalência no processo de experiência audiovisual do espectador.

A poética do filme se caracteriza por uma proposta de análise invertida, já que parte de dados elementares para compreender como sua interação determinará efeitos no espectador. Assim, partir-se-á de um procedimento de decomposição que elegerá os meios (ordem dos materiais que produzem os efeitos), estratégias (programação de efeitos) e efeitos (execução dos meios e estratégias). Sucintamente, o campo dos materiais se dividirá em quatro aspetos (visuais, cénicos, sonoros e narrativos), ao passo que os efeitos da programação serão divididos em sensações, sentimentos e sentidos, que nos orientarão no processo de análise da obra audiovisual.

Abordamos a precariedade como marco orientador e conceitual, que embasa a construção da obra. Desse modo, iremos analisá-la a partir de três diretrizes, para expor sua articulação e implicações na programação do filme. Problematizaremos a construção do espaço, a mise-en-scène e as peculiaridades da imagem sob a ótica de uma poética audiovisual da precariedade, elegendo, para cada um destes aspetos citados, uma cena da obra, dividida em três fotogramas, analisados pela poética do cinema.

\section{0 espaço precário em Leona Vingativa}

Acerca do espaço, Bachelard (1972) afirma que a emergência de uma nova imagem traz consigo a potencialidade de estabelecer uma nova dinâmica relacionada à sua ligação com o despertar de um arquétipo na esfera do inconsciente, revelando a potência de uma repercussão, cuja emergência está dissociada de uma causalidade, mas, sobretudo, de um mistério acerca de seus efeitos. Bachelard aponta que "a imagem poética não está submetida a um impulso. Não é o eco de um passado. É antes o inverso: pela explosão de uma imagem, o passado longínquo ressoa em ecos e não 
se vê mais em que profundidade esses ecos vão repercutir e cessar" (Bachelard 1972, 5).

Neste contexto, em que a imprevisibilidade orienta os efeitos de uma imagem sobre o seu espectador, a construção audiovisual da precariedade é enfatizada em sua dimensão espacial na websérie Leona Vingativa.

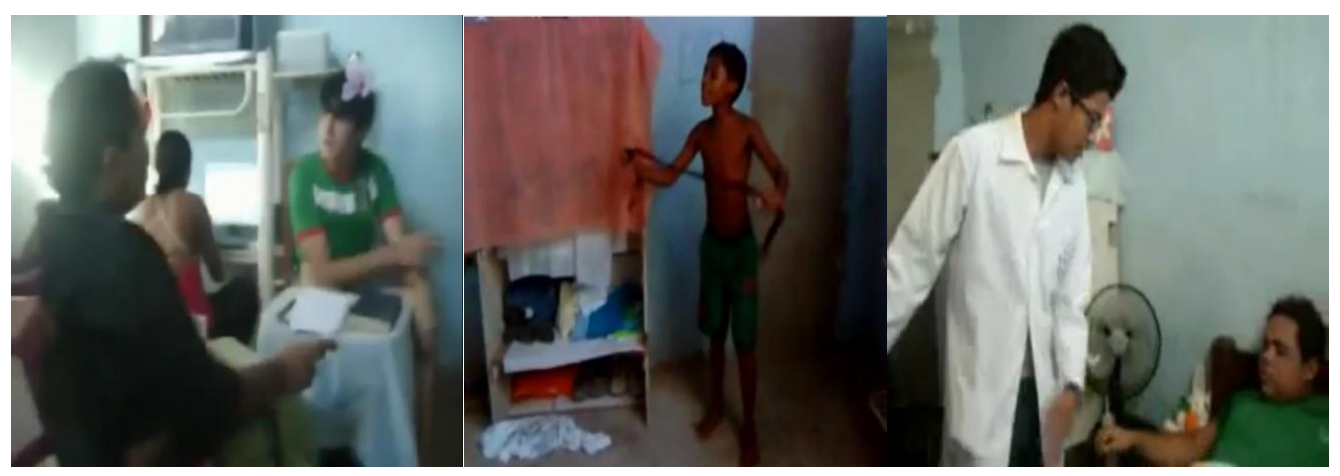

Imagem 1-3: 0 espaço precário em Leona Vingativa. Fotogramas dos episódios 2, 1 e 3, respetivamente. (C) Criadores (YouTube).

Analisando os fotogramas (1-3), que correspondem à organização estética do espaço feita pela websérie, estabelece-se com o espectador uma relação pactual cujo principal efeito é desestabilizar o olhar habituado a retóricas do audiovisual hegemónicas, onde competência e habilidade técnica são diluídos em favor de uma experiência pautada pela emergência poética da precariedade, como nova forma de sensibilidade. Segundo Rezende,

[e]sses recursos e expedientes não inertes e imparciais, nem simples intermediários prontamente substituíveis, que transportam significados da mente do autor para a materialidade da obra. Eles estão relacionados a um contexto sociocultural específico e trazem em si conceitos peculiares, portando-se como motores de transformação sensorial e intelectual e fomentando mudanças estéticas, já que modificam a conceção da obra, bem como sua forma ou estilo. (Rezende 2017, 11)

Um aspeto que merece atenção está diretamente relacionado aos reflexos das condições materiais na construção do espaço precário, uma vez que é na interação entre o Queer Caboclo e o espaço periférico que se elabora uma nova sensibilidade.

A análise dos aspetos cénicos da obra, evidencia que cada espaço enumerado pelas imagens traz uma relação direta com uma estética de 
improviso. Desse modo, a organização dos elementos no interior de cada cena reflete um duplo efeito: estabelecem uma dimensão diegética e incorporam dados contextuais ao espaço, produzindo uma poética espacial em que a precariedade não se origina unicamente da carência de recursos cénicos. Cada objeto disposto no cenário cumpre a função de ressignificar sua utilidade dentro do espaço precário: a estante que sustenta a televisão da casa transforma-se numa mesa que abriga a digitadora, que redige a denúncia da personagem (fotograma 1), os sapatos, roupas e outros utensílios empilhados numa caixa coberta por um pedaço de tecido se transformam num armário (fotograma 2), enquanto que o ventilador e a cama ressurgem na trama como mobiliários de um hospital (fotograma 3).

Nessa cenografia, orientada pela contingência e pela disponibilidade de recursos possíveis para a produção de cada espaço, a própria casa readquire significados, uma vez que renuncia sua função tradicional para ressurgir como um macrocosmo em que cada compartimento está sujeito aos imperativos do devir: a gambiarra, conceito socioestético fundamentado na reconfiguração de sentido aos objetos num dado contexto de uso, emerge como força motriz, alimentando a construção do espaço precário. Souza afirma que

[a] gambiarra está associada a uma série de eventos que envolvem as soluções advindas das necessidades imediatas, nas quais o sujeito da ação executa as tarefas sem as ferramentas e a matéria-prima adequadas, redefinindo usos e design, apropriando-se daquilo que tem nas mãos e utilizando artefactos sem se importar com a função estética. (Souza 2011,3)

Tal experiência traz a emergência de uma marca amadora à websérie que, embora revele traços socioeconómicos do elenco (ausência de recursos técnicos sofisticados, cenografia de improviso, eventuais erros de gravação, que funcionam como desmantelamento do espaço diegético), instauram um domínio que se distancia de tais marcadores, operando estratégias que se deslocam da tematização da realidade pelo discurso midiático institucional, recriando o estatuto das representações a partir de ações autónomas. Nesta direção, Zanetti, destaca que

[p]ara além da nossa vivência "real", conseguimos perceber, imaginar e idealizar o espaço onde vivemos em grande parte através dos processos de significação engendrados pela mídia que, num sentido mais amplo, engloba distintas formas de significação através de plataformas textuais e audiovisuais direcionadas a um 
público mais amplo. É nesse contexto que as periferias e favelas emergem no âmbito da produção midiática, tornando-se não apenas consumidoras e espectadoras de narrativas ficcionais e documentais do cinema e da televisão, mas também suas personagens principais e, muitas vezes, seus próprios agentes criadores. (Zanetti 2010, 11)

A construção do espaço precário é, portanto, uma experiência de ressignificação que envolve a interação do corpo e seu entorno, facilitada pelo imediatismo dos objetos disponíveis para sua consecução. Na realização cenográfica da websérie, enfatiza-se, portanto, a materialidade de cada objeto na economia estética do ambiente, uma vez que a significação do espaço está diretamente relacionada ao modo como foram organizados na cena e, também, na relação que os atores estabelecem com ele para atingirem os objetivos a que se destina a obra. De acordo com Gambarato,

\begin{abstract}
Um objeto relevante e expressivo certamente executará uma ou mais funções dentro do contexto do filme. Isso significa que a funcionalidade é incorporada em ambos os critérios de relevância e expressividade. Estaremos convencidos de que tal objeto se tornará um forte candidato para ser um objeto de desejo, em outras palavras, um elemento conscientemente selecionado pelo cineasta. Tal objeto é escolhido não apenas por suas qualidades cenográficas, materialidade ou qualidades físicas, mas também pelo seu valor comunicativo. (Gambarato 2009)
\end{abstract}

Ao colocar em prática o processo de rearticulação de sentido aos objetos no espaço cenográfico, a websérie instaura um olhar sobre o espaço, evidenciando a intimidade, à parte de pressupostos ancorados numa suposta neutralidade, para projetá-los no ecrã como uma experiência de improvisação que joga com os sentidos a fim de lhes estabelecer outros significados. Trata-se de um insistente processo de tradução, em que os objetos do entorno e sua própria imagem não figuram como limitações, mas sim como transbordamentos de significados que explodem no espaço representado.

\title{
6. Mise-en-scène precária em Leona Vingativa
}

Sobre mise-en-scène, Ramos (2012) resgata um conceito cuja influência remonta ao teatro do século XIX para compreender a organização do corpo e das coisas dentro do espaço da cena. Com a afirmação do cinema 
como arte, desenvolvimento de sua linguagem e gradual distanciamento da influência das vanguardas plásticas, o conceito de mise-en-scène foi reabilitado de modo a enfatizar a organização dramática no espaço cénico. Para o autor, "mise-en-scène no cinema significa enquadramento, gesto, entonação da voz, movimento no espaço. Define-se na figura do sujeito que se oferece à câmera na situação da tomada, interagindo com outrem que, por trás da câmera, lhe lança o olhar e dirige sua ação" (Ramos 2012, 53). Segundo Ramos, a organização do espaço cénico está imbuída de aspetos relacionados à interação entre ator, entorno e câmera, numa relação que enfatiza a dimensão performática como eixo pelo qual o drama se manifesta. Assim, a ideia de realçar a mise-en-scène teria como consequência direta a valorização de elementos estilísticos, que lhe dariam a alcunha de arte moderna, uma vez que seus elementos composicionais dariam sustentação a esse termo reabilitado pela crítica cinematográfica francesa, na década de 1950.

Ao enfatizar gesto, entonação e movimento no quadro, a mise-en-scène na websérie em questão estabelece, também, um diálogo com a categoria do camp, termo que define um tipo de sensibilidade pautada pela tradução da vida em termos de estilo, teatralidade e artifício (Sontag, 2005). Desse modo, a ideia de tradução da vida numa performance desnaturalizada e pautada pelo exagero traz uma sensibilidade sui generis, cuja influência será fundamental para a análise das relações entre mise-en-scène $\mathrm{e}$ precariedade em Leona Vingativa.

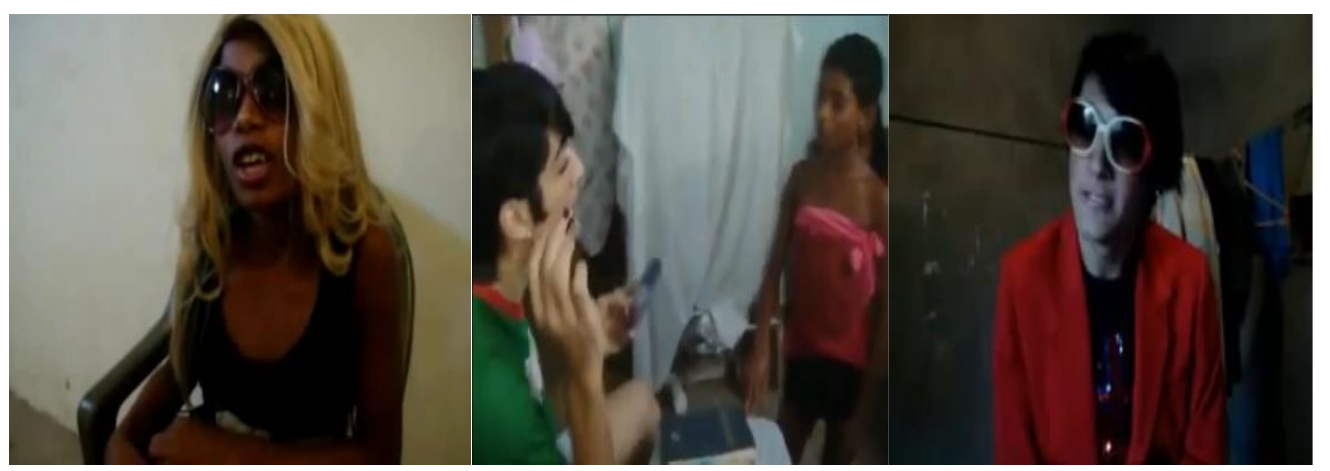

Imagem 4-6: A Mise-en-scène precária em Leona Vingativa. Fotogramas dos episódios 3, 2 e 3, respetivamente. (C) Criadores (YouTube).

Analisando os elementos visuais de cada fotograma, percebe-se uma exploração de tons como o vermelho, rosa, amarelo e verde, que sobressaem em relação ao fundo. Ao usar planos mais fechados, os 
fotogramas potencializam informações visuais que visam ressaltar traços fisionómicos de cada ator durante sua performance, assim como suas ações e maneirismos. Embora a nitidez das imagens não contribua para uma expressividade destes dados em todos os fotogramas (caso do fotograma 5), sobressaem em cada cena a expressividade cromática que choca com a cor do fundo, numa captação que faz uso da luz natural, com uso de câmera na mão.

Relativamente aos elementos sonoros, permanecem durante todas as cenas interferências de ruídos externos, acrescidos de recursos como vinhetas de telenovelas mexicanas (fotograma 4), que potencializam a expressividade performática da personagem, centralizada em um plano mais fechado.

Quanto aos elementos cénicos, prevalecem na cena o uso de figurinos e ornamentos aludindo a personagens de telenovelas mexicanas. Tal opção, marcada pelo rebuscamento no uso de cores expressivas, potencializa-se por meio de maneirismos do elenco, cuja influência de exageros próprios dos personagens destas referências televisivas marca um domínio dramatúrgico que retoma os pressupostos de uma encenação exagerada e artificial, utilizando figurinos e atuação como motivos paródicos de tais referências. 0 resultado é uma produção de significados baseada na apropriação de signos de outros produtos audiovisuais para a emergência de uma dramaturgia do Queer Caboclo, que se comunica ao espectador pela ênfase em sua performatividade. No travestimento da personagem (fotograma 5) verifica-se o tom satírico da delegada ouvindo o depoimento enquanto usa rímel e vê sua imagem refletida no DVD que traz evidências do crime cometido por Leona (fotograma 5) e no uso de ornamentos kitsch, como óculos e blusas com brilhos envoltos num terno vermelho, usados pela personagem no fotograma 6. Refletindo sobre a paródia nas artes, Hutcheon (1985) afirma que sua constante presença nas artes, a partir do século XX, decorre da desconfiança de uma crítica exterior, que teria como consequência a inserção de um comentário crítico, diluído na própria obra, e a produção de obras com cunho autorreflexivo. 0 autor conclui que:

É no contexto geral desta interrogação moderna acerca da natureza da autorreferência e da autolegitimação que surge o interesse contemporâneo pela paródia, género que foi descrito simultaneamente como sintoma e como ferramenta crítica do epistema modernista. (Hutcheon 1985, 12) 
Ao incorporar à websérie a influência de uma dimensão camp, onde a paródia se sobrepõe como tónica da obra, percebe-se como Leona Vingativa articula sua mise-en-scène como um processo de apropriação de referências populares com vista à produção de um distanciamento dos próprios marcadores de que se apropria. Delega-lhes assim novos significados e produz efeitos distintos daqueles para os quais foram anteriormente produzidos. Toma-se aqui a sensibilidade do Queer Caboclo, que desenha um espaço de disputa com as imagens hegemônicas, corroborando os dizeres de Butler:

Este não é um modo de se apropriar da cultura dominante para poder permanecer subordinada aos seus termos, mas sim uma apropriação que visa transgredir os termos da dominação, uma transgressão que é em si mesma uma capacidade de atuar, um poder no discurso e como discurso, na atuação e como atuação, que repete para poder recriar e, às vezes, consegue. (Butler 2002, 1999)

Se, até então, a influência melodramática que atravessa tais referências alusivas trazia consigo o desenvolvimento de uma relação física entre obra e espectador, em Leona tal fisicalidade dá lugar à retórica do deboche e da artificialidade, dinamitando a relação dramatúrgica em nome de uma mise-en-scène estreitamente ligada aos protocolos do esteticismo camp, como numa espécie de relação antropofágica cujo consumo se presta aos expedientes da ressignificação.

\section{A imagem precária em Leona Vingativa}

Propondo uma origem comum para a política e para a estética, Rancière (1995) institui o conceito de "partilha do sensível" para apresentar a possibilidade de construção de uma comunidade política baseada na confluência de perceções distintas, as quais modelariam o regime democrático por meio de expressões múltiplas no interior desta comunidade. A constituição estética pode ser entendida, segundo o filósofo francês, como:

O modo como se determina no sensível a relação entre um conjunto comum partilhado e a divisão de partes exclusivas. Antes de ser um sistema de formas constitucionais ou de relações de poder, uma ordem política é uma certa divisão das ocupações, a qual se inscreve, por sua vez, em uma configuração do sensível: em uma relação entre os modos do fazer, os modos do ser e os do dizer, entre a 
distribuição dos corpos de acordo com as atribuições e finalidades e a circulação do sentido; entre a ordem do dizível e a do visível. (Rancière 1995, 7-8)

Para este autor, a partilha aproxima categorias da estética e da política, demonstrando que ambas possuem uma origem comum, e, sobretudo, pontuando relações desiguais de visibilidade decorrentes da institucionalização de protocolos, códigos e normas institucionais para formas culturais. Desse modo, ao discutir sobre os regimes de visibilidades das obras de arte, destaca que há uma dimensão política responsável pela produção de formas de experiência. Tal dimensão ocupa-se dos modos de ver, das formas de dizer o que se vê e das supostas capacidades para ver (Ranciére 2005).

Ao considerarmos o elemento político e suas implicações nas formas de visibilidade, coloca-se em questão, também, a reflexão sobre o espaço desigual ocupado por formas de produção criativa na agenda midiática, a invisibilidade de trabalhos artísticos nos catálogos de mostras, nos espaços culturais e outros territórios destinados à sua difusão. Assim, tais produções têm emergido como potências políticas na contemporaneidade, reorganizando as formas de partilha do sensível, rearticulando seu status de visibilidade em outros espaços de difusão, possibilitados com a ascensão da internet de banda larga e difusão das mídias móveis, que resultam na valorização de uma ética e estética do amadorismo. A ausência de habilidades técnicas, de instrumentos sofisticados e de acesso a espaços de difusão tem como consequência um processo de valorização da imagem precária como força estética e política na contemporaneidade, chegando a influenciar inclusive a produção massiva de mídias hegemónicas (Polydoro e Costa 2014). 

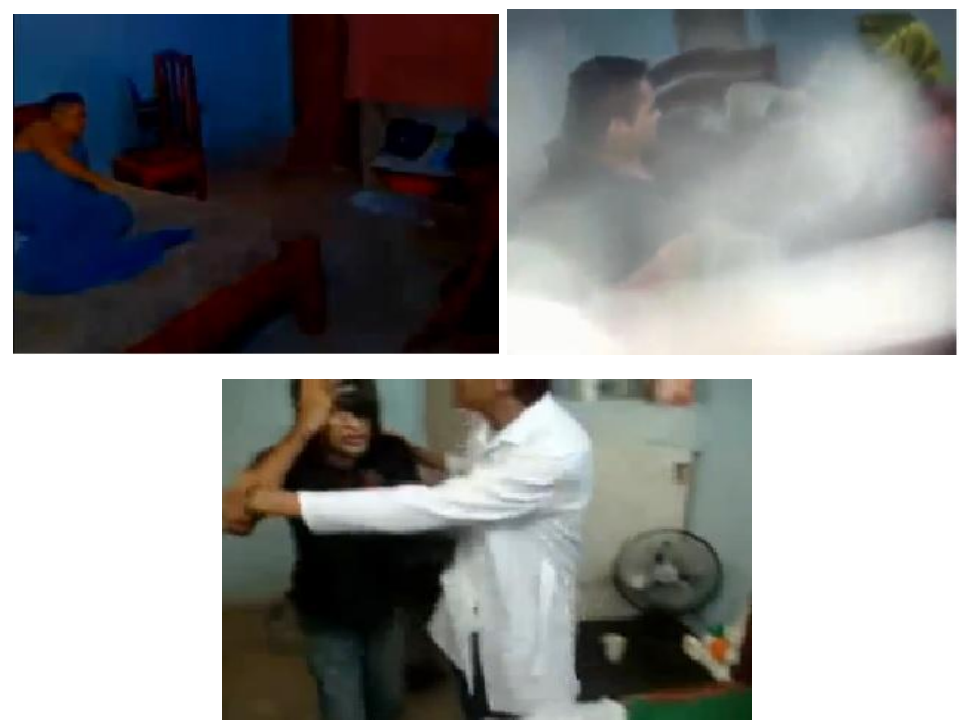

Imagem 7-9: A Imagem Precária em Leona Vingativa. Fotogramas dos episódios 1, 2 e 3, respetivamente. C Criadores (YouTube).

Há duas unidades comuns aos três fotogramas selecionados: a captação das cenas feita com câmera na mão e a ausência de resolução que possibilite visualizar de forma clara os trechos das cenas de cada um dos volumes da websérie. Este facto simultaneamente compromete aspetos relativos à visualização das ações e agrega valor ao elemento precário, o qual atravessa a produção.

No âmbito da análise dos materiais visuais, percebe-se que, no fotograma 7, a organização dos motivos no quadro compromete a visualização da personagem protagonista. A ausência de iluminação permite deduzir a presença de um personagem na margem inferior direita do quadro, mas os critérios de nitidez não oferecem informações para sua identificação. Se, no fotograma 7, a ausência de iluminação compromete a resolução da cena, no fotograma 8 é o excesso de luz que prejudica a qualidade da imagem do vídeo, cuja luz estourada compromete aspetos de foco e, sobretudo, fotográficos. No fotograma 9, embora a resolução não seja demasiadamente prejudicada, a questão relativa ao enquadramento dos personagens, decorrente do uso da câmera destituída de um suporte de estabilização e de uma direção limita a mobilidade dos atores no espaço. Embora tais dados fujam dos protocolos relativos a uma produção cinematográfica dita "de qualidade", cada um deles opera como uma fórmula destinada a introduzir tais "erros" como componentes destinados a oferecer sentidos distintos à obra, operando, portanto, dentro de outras normativas de afetação. 
Sobre a valorização destes elementos, considerados problemáticos, Ikeda e Lima $(2011,22)$ argumentam que, nas produções do século XXI, sobretudo as brasileiras, "a baixa resolução dos recursos de produção da imagem e do som é assumida e representa para alguns artistas uma maneira de subverter o fetiche do mainstream por uma alta definição da imagem. Subversão esta que também já foi incorporada".

Outro ponto é a interferência de aspetos relativos à sonoplastia, em que o uso do som ambiente é um recurso comum nos três últimos trechos salientados (Imagem 7-9). Incorporam-se na estética precária da produção ruídos, interferências e outros marcadores que transcendem o campo sonoro,

Por fim, a análise dos recursos propriamente cénicos evidencia o modo como a direção orienta o elenco da websérie e apresenta implicações em outros campos de análise, como o campo fotográfico, influenciando a construção dos enquadramentos e a mobilidade dos atores dentro do campo a ser captado. Isto abre espaço para valorização de uma estética mais aberta ao campo das improvisações, da incorporação dos erros de texto, de timing e outros elementos próprios do campo cénico.

\section{Considerações finais}

Com o advento do vídeo, um novo campo de experimentações coloca em xeque a reflexão acerca do estatuto realista da imagem, dando início a discussões que retomam a aproximação entre obra e público e, sobretudo, confundem as atribuições e espaços consolidados de realizador e espetador, incorporando domínios fluidos, complementares e ambivalentes no campo da produção cultural.

A cibercultura, a popularização da banda larga e o barateamento de tecnologias de captação de imagem dão continuidade a tal projeto revolucionário ao instituir a categoria do amador como potência, questionando os cánones das produções artísticas, revelando pontos de vista, releituras e, sobretudo, questionando as verdades sobre o outro, cristalizadas na produção midiática. Este esforço se dá no sentido de construir uma narrativa de autorrepresentação focada na reelaboração simultânea das representações sobre espaço, mise-en-scène e imagem precários onde o Queer Caboclo emerge como expressão. Tal movimento faz emergir novos processos de abordagem, em que signos da cultura de massas flutuam sob o efeito das influências de realizadores a quem a prerrogativa de difusão de seus produtos, outrora negligenciada, ganha 
espaço e repercussão no ciberespaço, favorecida pela eclosão de sites de compartilhamento de vídeo, que instituem novos formatos, modos de consumo, formas de difusão e fruição dos produtos audiovisuais ali difundidos.

Com a difusão de plataformas como Youtube, a websérie Leona Vingativa ganha reconhecimento do público e traz consigo a emergência da precariedade como marca que reverbera efeitos estéticos e políticos em sua produção. Revela assim ao espetador a potência que evidencia os domínios da autorrepresentação para disputar com imagens hegemónicas a reflexão sobre a identidade, representação, imaginário, dentre outros, que ampliam as políticas do olhar em favor da emergência de novas perspetivas, usos e práticas no âmbito da produção audiovisual contemporânea, marcando também o Queer Caboclo.

\section{Referências}

Bachelard, G. 1972. A Poética do Espaço. Rio de Janeiro: Eldorado.

Bazin, A. 1991. Cinema: Ensaios. São Paulo: Braziliense.

Borba, R. 2015. “Linguística Queer: uma perspectiva pós-identitária para os estudos da linguagem." Entrelinhas, 9 (1): 91-107.

Burgess, J. e Green, J. 2009. YouTube e Revolução Digital: como o maior fenômeno da cultura participativa transformou a mídia e a sociedade. São Paulo: Aleph.

Butler, J. 2017. Quadros de guerra: Quando a vida é passível de luto? Rio de Janeiro: Civilização Brasileira. . 2000. "Corpos que pesam: sobre os limites discursivos do "sexo"." In O corpo educado: pedagogias da sexualidade, ed. Guacira Lopes Louro, 151-166. Belo Horizonte: Autêntica.

. 2011. "Vida precária." Contemporânea - Revista de Sociologia da UFSCar. São Carlos, Departamento e Programa de Pós-Graduação em Sociologia da UFSCar (1): 13-33.

Cury, M. Z. F. 2013. "Poéticas da Precariedade". Estudos de Literatura Brasileira Contemporânea (41): 33-46.

Felinto, E. 2006. "Cinema e Tecnologias Digitais". In: História do cinema mundial, org. Fernando Mascarello, 413-428. São Paulo: Papirus. 
Fernandes, E. R. e F. S. Gontijo. 2016."Diversidade sexual e de gênero e novos descentramentos: um manifesto Queer Caboclo." Amazônica: Revista De Antropologia (Online). (8): 14-22.

Fraser, N. 2017. "Heterossexismo, Falso Reconhecimento e Capitalismo: Uma resposta a Judith Butler". Ideias. 8 (1): 277-94.

Gambarato, R. R. 2009. "Objetos falantes - metodologia de análise fílmica." Verso e Reverso (Unisinos. Online), 3. 23, no 54 Ano XXIII: 1-7. URL: http://revistas.unisinos.br/index.php/versoereverso/article/view/ $5771 / 3001$

Gomes, W. 2004. "La poética del cine y la cuestión del método en el análisis fílmico." Significação: Revista De Cultura Audiovisual, (31) 21: 85105.

Gunning, T. 2006 "The Cinema of Attraction[s]: Early Film, Its Spectator and the Avant-Garde." In Cinema of Attractions Reloaded, ed. Wanda Strauven, 381-388. Amesterdão: Amsterdam University Press.

Hutcheon, L. 1985. Uma Teoria da Paródia: Ensinamentos das formas de arte do século XX. Tradução: Tereza Louro Pérez. Lisboa: Edições 70.

Ikeda, M. e Lima, D. 2011. Cinema de Garagem - um inventário afetivo sobre o jovem cinema brasileiro do século XXI. Rio de Janeiro: WSET Multimídia.

Keen, A. 2009. O Culto do Amador: Como blogs, MySpace, YouTube e a pirataria digital estão destruindo nossa economia, cultura e valores. Rio de Janeiro: Jorge Zahar.

Levy, P. 1999. Cibercultura. São Paulo: Ed. 34.

Lyra, B. 2009. "Cinema periférico de bordas." Comunicação, Mídia e Consumo. (06) $15: 31-47$.

Marks, L. U. 2000. The Skin of Film: Intercultural Cinema, Embodiment, and the Senses. Durham: Duke University Press.

O’Reilly, T. 2007. "What is Web 2.0: Design Patterns and Business Models for the Next Generation of Software." Communications \& Strategies. (1) (First Quarter):17-37. https://mpra.ub.uni-muenchen.de/id/eprint/4578

Polydoro, F. S. e Costa, B. S. 2014. "A apropriação da estética do amador no cinema e no telejornal." Líbero (FACASPER) (1): 89-97. URL: http://seer.casperlibero.edu.br/index.php/libero/article/view/103 
Ramos, F. 2012. "A mise-en-scène realista: Renoir, Rivette e Michel Mourlet". In XIII Estudos de Cinema e Audiovisual - SOCINE, vol (no1) 53-68. São Paulo: SOCINE.

Rancière, J. 1995. Políticas da Escrita. Rio de Janeiro: Ed. 34.

Rea, C., e I. M. S. Amancio. 2018. "Descolonizar a sexualidade: Teoria Queer of Color e trânsito para o Sul." Cadernos Pagu (UNICAMP).(53): 1-38.

Rezende, P. D. 2017. Estética da Precariedade: A agência dos equipamentos técnicos na fotografia de Miroslav Tichy. Dissertação (Programa de Pós-Graduação Interunidades em Estética e História da Arte), São Paulo: USP.

Rizzo, T. 2008. "YouTube: A New Cinema of Attractions". Scan: Journal of Media, Arts, Culture. 5 (1). http://scan.net.au/scan/journal/display.php?journal_id=109

Sontag, S. 2005. Contra la Interpretación. Buenos Aires: Aguillar, Altea, Taurus, Alfaguara.

Souza, I. R. 2011. "A gambiarra: O Devir artefato." VI Reunião Científica da ABRACE. Porto Alegre. pp. 1-6.

Villar, G. 2014. "El arte contemporáneo y la precariedad." In Vidas Dañadas: Precariedad y vulnerabilidad en la era de la austeridade, ed. Sonia Arribas y António Gomez Villar, 75-95. Barcelona: Artefakte.

Zanetti, D. 2010. O Cinema de Periferia: Narrativas do cotidiano, visibilidade e reconhecimento social. Tese de Doutorado em Comunicação e Cultura Contemporânea, Salvador: UFBA.

Zanini, W. 2006. "Videoarte: Uma poética aberta." In: Crítica de Arte no Brasil: Temáticas Contemporâneas, por G. Ferreira. Rio de Janeiro: Funarte.

\section{Filmografia}

Leona, a Assassina Vingativa 1 [conteúdo gerado por usuário, online]. 2009. 4 mins e 10 segs.

https://www.youtube.com/watch?v=ACXFHGanR7w\&list=PLaAn20EnlVg idKFN6NZSeyJJPISWaZdJ-\&index=1 (último acesso: 11/12/2019).

Leona, Assassina Vingativa 2 [conteúdo gerado por usuário, online]. 2009. 9 mins e 20 segs. https://www.youtube.com/watch?v=Nc4cxludKFk\&list=PLaAn20E 
nlVgidKFN6NZSeyJJPISWaZdJ-\&index=2 (último acesso:

$11 / 12 / 2019)$.

Leona A Assassina Vingativa 3 - A Aliança Do Mal [conteúdo gerado por usuário, online]. 2009. 10 mins e 49 segs.

https://www.youtube.com/watch?v=XNmEf4-

HdMY\&list=PLaAn20EnlVgidKFN6NZSeyJPPISWaZdJ-\&index=3

(último acesso: 11/12/2019).

\title{
Audiovisual Poetics of Precariousness: An analysis of the web series Leona Vingativa
}

\begin{abstract}
This article discusses precariousness as a poetic category in the audiovisual, examining its relationship with the aesthetics of video and its influence in contemporary amateur productions, based on the analysis of the Leona Vingativa web series from the perspective of Queer Caboclo. This perspective establishes the category of the margin, the out-of-scene, the self-representations and the echoes of subalternized voices, thus reflecting the interactions, influences, desires and ways of seeing that underlie a new sensitive and countercultural order. The figure of the Queer Caboclo, of the Amazonian body, with its features and performativity, outlines a new epistemological turn, whose reflections reveal contradictions and a critical rhetoric that interferes in the formal and conceptual criteria of mass culture, resulting in a process of rearticulation of meanings with a political and subversive slant.
\end{abstract}

KEYWORDS precariousness; amateur video; web series; Leona Vingativa

Recebido a 13-6-2020. Aceite para publicação a 1-11-2020.

anikiEnsaios | Essays 